\title{
O Ecoturismo como alternativa sustentável para gestão da RPPN Catedral do Jalapão (TO)
}

\section{Ecotourism as a sustainable alternative for the management of the RPPN Catedral do Jalapão (TO, Brazil)}

\author{
Janaina Maria Andrade Aires Fonseca, Stella Maria Carvalho de Melo, \\ Wesley Gomes de Carvalho
}

RESUMO: A prática do turismo nas Unidades de Conservação (UC's) vem crescendo nos últimos anos. No Brasil, grande parte dos atrativos ecoturísticos encontra-se nas UC's, onde as Reservas Particulares do Patrimônio Natural (RPPN's) representam uma categoria de caráter privado. Essas unidades seguem uma tendência mundial de expansão dos esforços privados na conservação da biodiversidade, cujo uso compatível, por meio do turismo, é permitido, mediante planejamento e manejo adequados. O segmento do turismo que explora as UC's é chamado de ecoturismo, e começa a ser realizado em uma RPPN no Estado do Tocantins, Brasil. O objetivo deste estudo é investigar a prática do ecoturismo como alternativa para as RPPN's através de um estudo de caso na RPPN Catedral do Jalapão, analisando a gestão da atividade, o perfil e o fluxo de visitantes do local. Os procedimentos metodológicos utilizados para o desenvolvimento da pesquisa são pesquisa bibliográfica e de campo, através de visitas in loco, entrevista com o gestor e aplicação de questionários com os visitantes. A pesquisa foi norteada pela questão da possibilidade de o ecoturismo vir a ser uma alternativa para a gestão sustentável de Unidades de Conservação de propriedade privada, cujos resultados demonstram tendências e práticas diversas sendo desenvolvidas nesses ambientes. Com esta pesquisa, verificou-se que a RPPN utiliza de uma arquitetura sustentável nas suas instalações, e que os principais motivos que levaram a sua criação foi a proteção da fauna e flora local e relevância ecológica da sua localização. Percebeu-se que os visitantes buscam curtir na natureza que a região proporciona, além das práticas de atividades de ecoturismo, promovendo um contato com o meio ambiente local. Assim, constatou-se que a Catedral do Jalapão tem buscado através de suas práticas, cumprir com o papel socioambiental para o qual foi definida, sendo um modelo de sustentabilidade e boas práticas associadas ao ecoturismo.

PALAVRAS-CHAVE: Unidades de Conservação; Ecoturismo; RPPN. 


\section{ABSTRACT}

The practice of tourism in Protected Areas (PA) has been growing in recent years. In Brazil, most of the ecotourism attractions are found in the PAs, where Private Reserves of Natural Patrimony (RPPN's) represent a category of private sphere. These units follow a worldwide trend of expanding private efforts to conserve biodiversity, whose compatible use through tourism is permitted through appropriate planning and management. The tourism segment that explores PAs is called ecotourism, and begins to be held in an RPPN in the state of Tocantins, Brazil. The objective of this study is to investigate the practice of ecotourism as an alternative to the RPPN's through a case study in the RPPN Catedral do Japalão, analyzing the activity management, the profile and the flow of visitors to the area. The methodological procedures used for the development of the research are bibliographic and field research, through on-site visits, interview with the manager and application of questionnaires with the visitors. The research was guided by the question of the possibility of ecotourism becoming an alternative for the sustainable management of privately owned Protected Areas, whose results demonstrate diverse trends and practices being developed in these environments. With this research, it was verified that the RPPN uses a sustainable architecture in its facilities, and that the main reasons that led to its creation was the protection of local fauna and flora and ecological relevance of its location. It was noticed that the visitors seek to enjoy the nature that the region provides, besides the practices of ecotourism activities, promoting a contact with the local environment. Thus, it was found that the Catedral do Jalapão has sought through its practices to fulfill the socio-environmental role for which it was defined, being a model of sustainability and good practices associated with ecotourism.

KEYWORDS: Protected Areas; Ecotourism; RPPN.

\section{Introdução}

O turismo é uma das atividades econômicas de maior relevância, atualmente. Se bem planejado, pode promover o desenvolvimento das comunidades que têm potencial para tal e levar até a preservação ambiental. Esta atividade pode ser desenvolvida em diversos ambientes, principalmente em ambientes naturais.

A sua prática pode ocorrer nas chamadas Unidades de Conservação (UC's) e o segmento do turismo que explora estas UC's é conhecido como ecoturismo. O ecoturismo, surgido na década de 1980, representa uma modalidade de turismo com a proposta de integrar os princípios da sustentabilidade, em todas as suas instâncias (ecológica, econômica e sociocultural), ao caráter educativo da experiência do turista na natureza preservada, mediante mecanismos de sensibilização ambiental e o engajamento da comunidade local no processo de decisão acerca do desenvolvimento turístico, desde a concepção do processo, e numa perspectiva de longo prazo. O que se pretende é uma inter-relação entre ecologia e turismo, na forma em que "[...] o turismo e o meio ambiente encontrem um ponto de equilíbrio, a fim de que a atratividade dos recursos naturais não seja a causa da sua degradação" (RUSCHMANN, 2000, p.27).

Os atrativos turísticos naturais do Brasil estão, na sua maioria, localizados em Unidades de Conservação (UC's), que, por meio das 
atividades de uso público, tem apresentado demanda crescente de visitantes, trazendo um grande desafio para os gestores que é compatibilizar tais atividades respeitando os princípios de sua criação (CEGANA; TAKAHASHI, 2005). Apesar de abrigar um enorme patrimônio natural e cultural, as UC's recebem pouca atenção dos governos, tanto no seu planejamento ambiental quanto turístico, apresentando, na sua maioria, infraestrutura incipiente e ausência de recursos financeiros e humanos. Esse cenário de ameaças aos objetivos de criação das UC's, prioritariamente baseado em áreas públicas, tem apresentado uma oportunidade para implantação das Reservas Particulares do Patrimônio Natural (RPPN's).

A RPPN é uma categoria de UC que oficializa a iniciativa voluntária do proprietário privado de contribuir para a conservação dos ecossistemas. Nesses espaços, a atividade turística representa um dos possíveis usos públicos descritos na sua legislação, e o ecoturismo é visto como a modalidade com melhores possibilidades de integrar os objetivos de conservação e o uso compatível do ambiente natural. Uma UC tem como objetivo principal a conservação da natureza, determinando o seu manejo e buscando a utilização sustentável, a restauração ou a recuperação do ambiente natural. As RPPN's são Unidades de Conservação do tipo Uso Sustentável, onde é possível compatibilizar a conservação da natureza com o uso sustentável de parcela dos seus recursos naturais.

No extremo leste do Estado do Tocantins, especificamente no município de São Félix, foi implantado a RPPN Catedral do Jalapão. A formação rochosa (morro testemunho) em forma de uma catedral deu sentido ao nome do projeto de conservação, ecoturismo e campo de pesquisa: Fazenda Ecológica Catedral do Jalapão, objeto de estudo dessa pesquisa.

A prática do ecoturismo pressupõe a utilização sustentável dos recursos naturais, integrando os visitantes com a natureza, de forma que o meio ambiente não seja tão impactado. Neste cenário, entende-se que o ecoturismo pode ser uma importante atividade para a gestão das RPPN's. Assim, o ecoturismo pautado no desenvolvimento sustentável nas comunidades locais, pode promover o equilíbrio entre diversos interesses tais como a conservação dos recursos naturais, a melhoria das condições de vida da população local e o enriquecimento da experiência dos turistas.

Diante deste cenário, Pires (2002) destaca que a atividade ainda apresenta carência de estudos especializados. Nesse sentido, o presente estudo contribui para o melhor entendimento do ecoturismo e, mais precisamente, da sua atuação nas RPPN's, ampliando os conhecimentos ainda incipientes acerca das reservas privadas no Estado do Tocantins.

Deste modo, o objetivo desta pesquisa é investigar a prática do ecoturismo como alternativa para a gestão sustentável de RPPN's, através do estudo de caso na RPPN Catedral do Jalapão. Para tanto, buscou-se: levantar e descrever os atrativos turísticos e as atividades turísticas desenvolvidas na RPPN; identificar a infraestrutura de apoio e a infraestrutura turística existente; analisar o fluxo de visitantes da RPPN, identificando o seu perfil; e analisar a percepção do gestor do empreendimento quanto a importância do ecoturismo para a gestão da RPPN. 


\section{Materiais e métodos}

Esse artigo é classificado, metodologicamente, segundo seus objetivos, em uma pesquisa descritiva e exploratória, pois é feita uma descrição sobre o ecoturismo na RPPN e uma busca de informações sobre a região, já que não existem dados sobre esta temática, na localidade. Quanto aos procedimentos, a pesquisa pode ser classificada como bibliográfica e estudo de caso.

Conforme Santos (2016), a pesquisa bibliográfica é feita com base em documentos já elaborados e a pesquisa estudo de caso analisa com profundidade um ou poucos fatos e é usada em estudos exploratórios. A pesquisa bibliográfica abrange a leitura, análise e interpretação de obras escritas sobre o tema em estudo, como ecoturismo, desenvolvimento sustentável e local, com a finalidade de servir de fundamentação teórica ao trabalho.

A pesquisa estudo de caso foi feita a partir de uma pesquisa de campo, com observação direta do local de estudo, pelo registro fotográfico e pela coleta de dados, por meio da aplicação de formulários com perguntas abertas e fechadas e entrevista.

Foram realizadas duas visitas de campo para observação direta, durante os meses de outubro de 2016 e março de 2017, onde foram levantados e descritos os atrativos turísticos e as atividades turísticas desenvolvidas na RPPN e identificadas a infraestrutura de apoio e a infraestrutura turística existente no local.

Já os formulários foram aplicados com os visitantes da RPPN, no empreendimento Catedral do Jalapão, durante os meses de novembro de 2016 a março de 2017, período considerado de maior fluxo de visitantes, segundo informações dos proprietários. Foram identificados o perfil dos visitantes, a partir da investigação de dados como: idade, gênero, cidade onde mora, motivação da viagem, tempo de permanência e opinião sobre a localidade. Foram pesquisadas 59 pessoas que estavam na RPPN, durante a pesquisa de campo, e que se disponibilizam a participar desse trabalho.

No mês de março de 2017, foi realizada, também, uma entrevista estruturada com o proprietário e gestor da RPPN, com a finalidade de compreender melhor sobre a criação e características do local.

A escolha da amostra dos visitantes a serem pesquisados foi do tipo não-probabilística e por conveniência, já que não se tem dados sobre a demanda turística do empreendimento e realizada, apenas, com as pessoas que aceitaram participar da pesquisa. Segundo Dencker (1998), a amostragem não-probabilística é utilizada quanto o universo da amostra é desconhecido e na amostragem por conveniência os elementos são escolhidos de acordo com a conveniência do pesquisador.

Após a coleta de dados, fez-se a tabulação e o processamento dos dados, de modo a obter subsídios suficientes para a compreensão da realidade investigada e a proposta de uma resposta à problematização construída. 


\section{Unidades de Conservação do Tocantins e o Ecoturismo} compreende 0

Segundo Brasil (2000, p.1), uma Unidade de Conservação

espaço territorial e seus recursos ambientais, incluindo as águas jurisdicionais, com características naturais relevantes, legalmente instituído pelo Poder Público, com objetivos de conservação e limites definidos, sob regime especial de administração, ao qual se aplicam garantias adequadas de proteção.

Desse modo, as UC's são espaços delimitados que buscam, principalmente a conservação ambiental. Elas são divididas em dois grandes grupos: Unidades de Proteção Integral e Unidades de Uso Sustentável. Conforme a Lei 9.985 , de 18 de julho de 2000, que regulamenta o art. 225, $\S$ 10, incisos I, II, III e VII da Constituição Federal, institui o Sistema Nacional de Unidades de Conservação da Natureza e dá outras providências, o "objetivo básico das Unidades de Proteção Integral é preservar a natureza, sendo admitido apenas o uso indireto dos seus recursos naturais" e o "objetivo básico das Unidades de Uso Sustentável é compatibilizar a conservação da natureza com o uso sustentável de parcela dos seus recursos naturais" (BRASIL, 2000, p.1).

De acordo com essa Lei, as UC's de Proteção Integral se dividem em: Estação Ecológica; Reserva Biológica; Parque Nacional; Monumento Natural; e Refúgio de Vida Silvestre. E as UC's de Uso Sustentável se dividem em: Área de Proteção Ambiental; Área de Relevante Interesse Ecológico; Floresta Nacional; Reserva Extrativista; Reserva de Fauna; Reserva de Desenvolvimento Sustentável; e Reserva Particular do Patrimônio Natural.

No Estado do Tocantins, existem 33 UC's com uma área total de 4.187.628,86 hectares, sendo oito do tipo Proteção Integral e 25 do tipo Uso Sustentável. A região do Jalapão está protegida por cinco Unidades de Conservação de proteção integral: a Estação Ecológica (ESEC) Serra Geral do Tocantins, a Estação Ecológica do Rio Preto, o Monumento Natural (MN) Canyons e Corredeiras do Rio Sono, o Parque Estadual (PE) do Jalapão e o Parque Nacional (PN) das Nascentes do Rio Parnaíba, representando o maior conjunto de Unidades de Conservação de proteção integral de todo o Cerrado. A região também abriga seis Unidades de Conservação de uso sustentável: as Áreas de Proteção Ambiental (APA) Serra da Tabatinga, do Jalapão e a do Rio Preto e as Reservas Particulares do Patrimônio Natural (RPPN) Catedral do Jalapão, Fazenda Calixto e Mina d'Água. Este conjunto de áreas protegidas soma aproximadamente 3.280.045 hectares e apresenta grande relevância para a proteção da biodiversidade brasileira e global, considerando o alto grau de fragmentação do bioma Cerrado e que a maior parte das áreas protegidas deste bioma apresentam áreas menores do que 50.000 hectares (BRASIL, 2013a).

O Jalapão se tornou a maior área protegida do Cerrado, abrangendo Unidades de Conservação na Bahia e no Tocantins reconhecido como 
Mosaico do Jalapão através da Portaria № 434, de 29 de setembro de 2016 (BRASIL, 2016).

De acordo com o Sistema Nacional de Unidades de Conservação da Natureza - SNUC, o Mosaico de Unidades de Conservação é um modelo de gestão de áreas protegidas que abrange unidades próximas, justas ou sobrepostas, pertencentes a diferentes esferas de governo ou de gestão particular, que busca a participação, integração e envolvimento dos gestores das unidades e da população local, com o intuito de compatibilizar a presença da biodiversidade, a valorização da diversidade social e o desenvolvimento sustentável em um contexto regional (BRASIL, 2013b).

Das Unidades de Conservação pertencentes ao Mosaico do Jalapão, três são geridas pelo Instituto Chico Mendes de Conservação da Biodiversidade (ICMBio): Parque Nacional das Nascentes do Rio Parnaíba; Estação Ecológica Serra Geral do Tocantins; e Área de Proteção Ambiental Serra da Tabatinga. Duas unidades estão sob gestão do Instituto de Meio Ambiente e Recursos Hídricos da Bahia (Inema): Estação Ecológica do Rio Preto; e Área de Proteção Ambiental do Rio Preto. O Instituto Natureza de Tocantins (Naturatins) é responsável pelo Parque Estadual do Jalapão e pela Área de Proteção Ambiental do Jalapão. Existe ainda uma unidade do município de São Félix do Tocantins, o Monumento Natural dos Canyons e Corredeiras do Rio Sono; e outra sob gestão privada, que é a Reserva Particular do Patrimônio Natural Catedral do Jalapão (BRASIL, 2013b).

De acordo com Soares e Adorno (2014), as Reservas Particulares de Patrimônio Natural no Estado do Tocantins abrangem uma área de aproximadamente 5496.74 hectares, este total de área transformada em RPPN coloca o estado do Tocantins na $15^{\text {a }}$ posição do ranking nacional. Porém, no Estado foram criadas dez RPPN's, localizadas nos municípios: Palmas, Pium, Lagoa da Confusão, Abreulândia, Almas, Dianópolis, São Félix do Tocantins e Aurora do Tocantins.

Dessa forma, a RPPN Catedral do Jalapão, localizada no município de São Félix, na região do Jalapão, é uma UC do tipo Uso Sustentável, sendo descrita na Lei 9.985 (BRASIL, 2000), como uma área privada, gravada com perpetuidade, com o objetivo de conservar a diversidade biológica, a partir da assinatura de um termo de compromisso assinado perante o órgão ambiental, que verificará a existência de interesse público, e será averbado à margem da inscrição no Registro Público de Imóveis. Ainda segundo esta Lei, em uma RPPN só pode ser permitida a pesquisa científica e a visitação com objetivos turísticos, recreativos e educacionais.

O Ministério do Meio Ambiente - MMA considera visitação como "o aproveitamento e a utilização da Unidade de Conservação com fins recreacionais, educativos, entre outras formas de utilização indireta dos recursos naturais e culturais" e entende 'visitante' como toda pessoa que frequenta uma UC, de acordo com os objetivos de cada local, incluindo turistas, excursionistas e a comunidade local (BRASIL, 2006, p.9). Esta definição técnica compreende as mesmas distinções feitas por Beni (2003), onde tanto turistas quanto excursionistas são visitantes temporários em uma localidade, em que os turistas são aqueles que permanecem pelo menos 
vinte e quatro horas no destino, e os excursionistas são aqueles que ficam menos de vinte e quatro horas no local visitado.

De acordo com o Decreto 5.746, de 5 de abril de 2006, as RPPN's serão criadas, somente, em áreas de posse e domínio privados, pelos órgãos integrantes do SNUC, sendo que, no âmbito federal, serão declaradas instituídas mediante portaria do Instituto Brasileiro do Meio Ambiente e dos Recursos Naturais Renováveis - IBAMA (BRASIL, 2006).

Deste modo, a prática de visitação turística em Unidades de Conservação deve ser bem planejada e controlada para minimizar os impactos ao meio ambiente. A inserção do meio ambiente ao processo de desenvolvimento turístico requer mudanças de comportamento, buscando um desenvolvimento equilibrado entre a atividade turística e o ambiente natural, que preserve os recursos naturais necessários para a manutenção da sustentabilidade. Para Vera et al. (1997), isto só é possível através de uma abordagem global, que contemple as dimensões econômicas, ecológicas e culturais.

Segundo Silva (2008, p.58),

o turismo precisa constituir mais um aliado ao manejo sustentável das Unidades de Conservação, reconhecendo que não cabe a um organismo ou instituição toda a responsabilidade de bem gerir a área. Pelo contrário, todos os que influenciam e dependem da UC, possuem papel de destaque para mitigar os impactos sobre o meio ambiente. Seja por suas condutas, seja pela prestação de serviços e informações capazes de satisfazer a demanda e conscientizar da importância da preservação e conservação da natureza.

Assim, o desenvolvimento do turismo nas UC's deve ser feito de forma responsável, evitando a degradação ambiental e a destruição dos ambientes, que foram razão principal para a criação das áreas protegidas. Esta preocupação é importante, pois, em muitos casos, ao invés de contribuir para a conservação dos ambientes naturais que compõem, acabam provocado impactos sociais e ambientais nessas áreas, além de não gerar recursos econômicos necessários para a esperada sustentabilidade desses espaços.

Segundo o MMA (BRASIL, 2006, p.10), no documento 'Diretrizes para Visitação em Unidades de Conservação',

O turismo, ao mesmo tempo em que fortalece a apropriação das Unidades de Conservação pela sociedade, incrementa a economia e promove a geração de emprego e renda para as populações locais. Por outro lado, o desafio consiste em fazer com que o turismo seja desenvolvido de maneira harmônica e integrada para que a atividade não prejudique a manutenção dos processos ecológicos, a diversidade sociocultural e conhecimentos tradicionais e a conservação 
da biodiversidade. A visitação em Unidades de Conservação também funciona como uma forma de incrementar o apoio econômico para a conservação da natureza nestas áreas e potencializar a utilização sustentável dos serviços vinculados aos ecossistemas.

A geração de recursos econômicos, oriundos do turismo para as UC's são fundamentais para sua manutenção e gestão. Segundo o Centro para Monitoramento da Conservação Mundial do Programa das Nações Unidas para o Meio Ambiente - UNEP-WCM, a visitação nos Parques Nacionais existentes no Brasil tem potencial para gerar entre $R \$ 1,6$ bilhão e $R \$ 1,8$ bilhão por ano, considerando as estimativas de fluxo de turistas projetadas para o país (cerca de 13,7 milhões de pessoas, entre brasileiros e estrangeiros) até 2016, e a soma das estimativas de visitação pública nas Unidades de Conservação federais e estaduais indica que, se o potencial das unidades for adequadamente explorado, cerca de 20 milhões de pessoas visitarão essas áreas em 2016, com um impacto econômico potencial de cerca de $R \$ 2,2$ bilhões naquele ano (MEDEIROS et al, 2011). Estas estimativas poderiam ser também atribuídas às outras UC's que permitem visitação turística, como as RPPN's.

Ainda conforme o UNEP-WCM,

a visitação nas 310 Unidades de Conservação federais consideradas pelo estudo tem potencial de atrair cerca de 17,5 milhões de pessoas em 2016. O impacto econômico estimado por esse turismo é de, aproximadamente, entre $\mathrm{R} \$ 1,8$ (cenário conservador) e $\mathrm{R} \$ 2$ bilhões (cenário otimista) nas regiões onde estão localizadas essas Unidades de Conservação, garantindo recursos para sua manutenção e dinamizando a economia local (MEDEIROS et al., 2011, p.23).

A renda gerada é conquistada a partir da venda de ingressos, arrecadação pelas taxas para realização de atividades recreativas, estacionamento, venda de alimentos, venda de souvenires, entre outros. Assim, utilizar-se do turismo para conseguir manter uma UC é uma alternativa rentável, se for bem administrada.

Uma das formas de se desenvolver o turismo em áreas naturais é através da prática do ecoturismo. Conforme a Sociedade Internacional de Ecoturismo, o ecoturismo ou turismo ecológico é uma categoria do chamado turismo de natureza, que é aquele praticado em contato com a natureza. Ainda segundo esta organização, a prática ecoturística é uma viagem responsável para áreas naturais que conservam o meio ambiente, mantém o bem-estar da comunidade local e que envolve interpretação e educação (TIES, 2015).

Já para Ministério do Turismo - Mtur, o ecoturismo é "o segmento da atividade turística que utiliza, de forma sustentável, o patrimônio natural e cultural, incentiva sua conservação e busca a formação de uma consciência 
ambientalista por meio da interpretação do ambiente, promovendo o bemestar das populações" (BRASIL, 2010, p.17).

O segmento ecoturístico é recente, com suas primeiras pesquisas no país, datando a década de 1980, surgindo como uma alternativa para o turismo tradicional. Segundo o Mtur, o

ecoturismo possui entre seus princípios a conservação ambiental aliada ao envolvimento das comunidades locais, devendo ser desenvolvido sob os princípios da sustentabilidade, com base em referenciais teóricos e práticos, e no suporte legal. O desenvolvimento sustentável é um conceito que visa harmonizar o crescimento econômico com a promoção da igualdade social e preservação do patrimônio natural, garantindo que as necessidades das atuais gerações sejam satisfeitas sem, contudo, comprometer o atendimento às necessidades das gerações futuras (BRASIL, 2007, p. 20).

Assim, reconhece-se a importância das práticas sustentáveis pelo ecoturismo. Entretanto, não se deve confundir ecoturismo com turismo sustentável. O ecoturismo é um segmento do turismo, enquanto o turismo sustentável deve ser aplicado em todos os tipos de turismo. Segundo a OMT (2003, p.23), o turismo sustentável é aquele que:

\begin{abstract}
atende às necessidades dos turistas de hoje e das regiões receptoras ao mesmo tempo em que protege e amplia as oportunidades para o futuro. É visto como condutor ao gerenciamento de todos os recursos, de tal forma que as necessidades econômicas, sociais e estéticas possam ser satisfeitas sem desprezar a manutenção da integridade cultural, dos processos ecológicos essenciais, da diversidade biológica e dos sistemas que garantam a vida.
\end{abstract}

Deste modo, o ecoturismo é um tipo de turismo desenvolvido em ambientes naturais e sua prática deve sempre buscar a sustentabilidade, evitando que estes ambientes sejam degradados, o que comprometeria não só a qualidade da visitação, mas a continuação da prática turística em si.

\title{
Resultados e discussões
}

\section{A RPPN Catedral do Jalapão e a Gestão do ecoturismo}

A RPPN Catedral do Jalapão compreende uma área 325.65ha, constitui-se parte integrante da Fazenda denominada Fazenda Ecológica Catedral do Jalapão, está situada à leste do Tocantins, na Mesorregião Oriental do Tocantins, Microrregião do Jalapão, no município de São Félix do Tocantins (TO).

A Unidade de Conservação nasceu de um projeto pessoal do proprietário, que é geógrafo, de deixar um legado na área ambiental, tendo 
em vista sua formação acadêmica e valores pessoais adquiridos ao longo da sua trajetória profissional no campo do meio ambiente.

No seu primeiro contato profissional com a região do Jalapão, o seu atual proprietário percebeu que o local era interessante para 0 desenvolvimento de pesquisas e projetos de conservação. Em 2005, iniciou um trabalho de pesquisa no Parque Estadual do Jalapão que o aproximou da região e, desde então, iniciou a busca por uma área que pudesse criar um laboratório de pesquisa. Entre 2005 a 2010, o proprietário desenvolveu várias pesquisas enquanto professor da Universidade Federal do Tocantins e, nesta ocasião, adquiriu o imóvel Fazenda Ecológica Catedral do Jalapão, com 1.060ha. Desde então, percebeu que poderia transformar parte da área em uma RPPN e assim agregar a prática do ecoturismo à conservação do local.

A Catedral do Jalapão conta com uma área protegida de caça e queimadas, desde 2008, e em 27 de julho de 2010, por meio da portaria $\mathrm{n}^{0}$ 58, recebeu o título de RPPN via Ministério do Meio Ambiente e ICMBio. Entretanto, somente em novembro de 2014, começou a operar comercialmente a atividade ecoturística através do Jalapão Ecolodge, um empreendimento ecoturístico localizado na propriedade, fora dos limites da RPPN.

O Jalapão Ecolodge é um estabelecimento comercial destinado à conservação e ao ecoturismo que tem como missão promover a conservação ambiental e oferecer serviços turísticos que proporcionem o avivamento da busca interior do ser com a natureza.

O termo Ecolodge é descrito por Nelson e Pereira (2004, p. 321):

O vocábulo "lodge", considerado isoladamente, significa alojamento, porém, quando acrescido da partícula eco, adquire um significado mais restrito. Conforme Russell, Bottrill e Meredith (1995 apud NELSON, op cit, p. 321) "lodge" é um termo genérico e engloba os hotéis tradicionais localizados em áreas de belezas naturais (nature-based lodge) como hotéis de pesca, hotéis em estações de esqui, resorts de luxo, entre outros. Já "ecolodge" (nature dependent tourist lodge) é uma rotulação utilizada para identificar os hotéis que baseiam suas atividades na natureza, seguindo a filosofia e os princípios do ecoturismo. Portanto, é essencial compreender que o fato de o estabelecimento estar localizado numa área natural ou ser denominado lodge/hotel ecológico/hotel de selva não é suficiente para fazê-lo ecoturístico.

Outro aspecto importante citado por Nelson e Pereira (2004) é que os ecolodges, enquanto equipamentos ecoturísticos, devem ser projetados de acordo com as premissas da arquitetura sustentável. Seus projetos precisam conciliar um meio de vida menos consumista, e nem por isso menos confortável, com a proteção dos recursos, demonstrando que 
desenvolvimento e conservação podem andar juntos. Isto quer dizer que os prédios devem ser esteticamente prazerosos, misturando-se, harmoniosamente, com o entorno, enfatizando a utilização de ecotécnicas.

Dessa forma, o Jalapão Ecolodge utiliza-se da arquitetura sustentável nas unidades de hospedagem elaboradas por princípios de bioarquitetura chamadas de "buritibanas" 1 que acomoda até quatro pessoas e um bangalô panorâmico construído no topo de um morro e proporcionando uma vista exclusiva da Serra da Catedral, equipado com cama de casal, sacada com chuveiro e jacuzzi (Figura 1). Além disso, o local oferece também área de camping com opção de aluguel de barracas para hospedagem
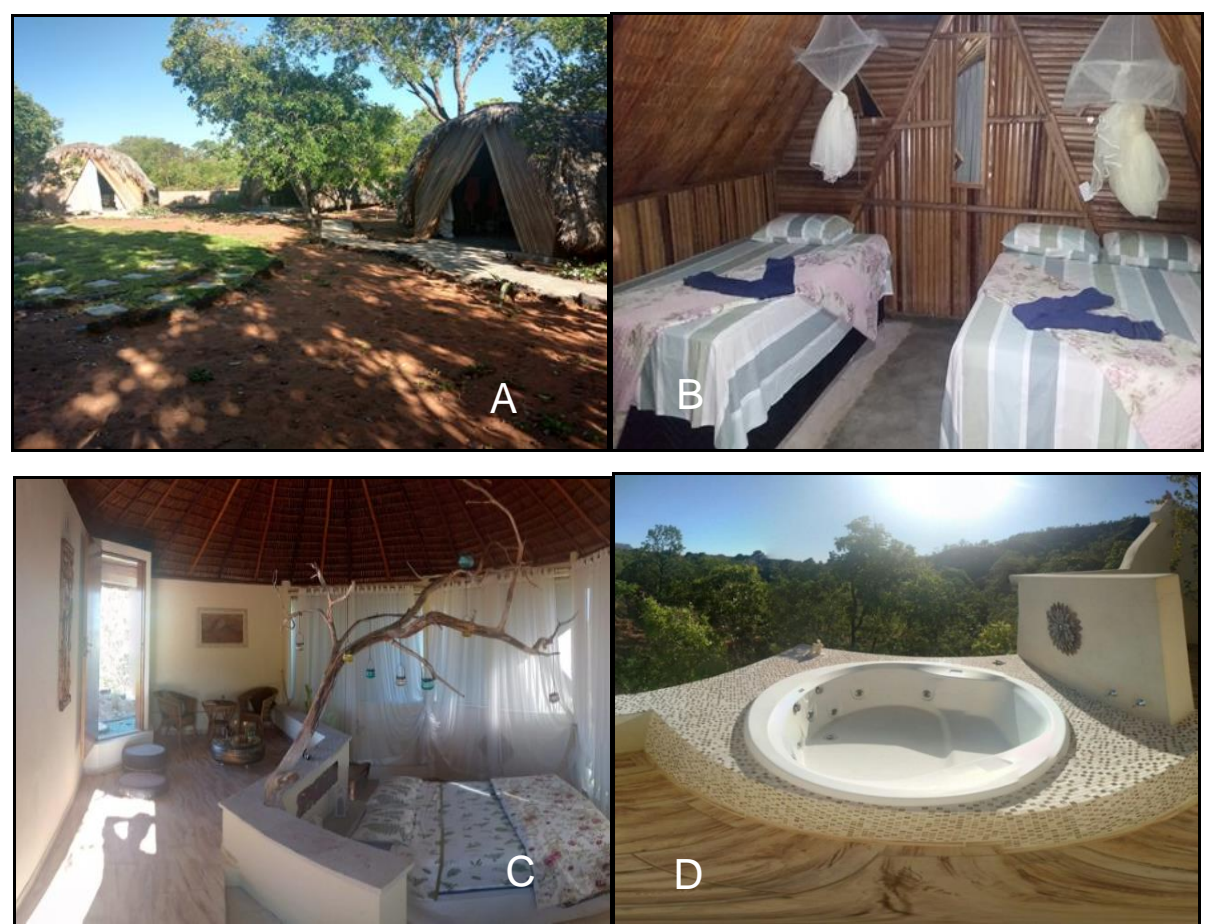

Figura 1: Fotografias dos locais de hospedagem do Ecolodge - A: vista externa das buritibanas; B: vista interna das buritibanas; C: vista interna do bangalô; D: jacuzzi do bangalô. Fonte: Pesquisa de campo, out./2016.

Figure 1: Photographs of the lodging sites of the Ecolodge - A: external view of the buritibanas; B: internal view of the buritibanas; C: internal view of the bungalow; D: bungalow's jacuzzi. Source: Field research, Oct./2016.

O Jalapão Ecolodge oferece opções de hospedagem com café da manhã e passeios. Os passeios são guiados por condutores locais e incluem caminhadas para observação de fauna e conhecimento do ecossistema nas trilhas ecológicas, canoagem e banho na Enseada e prainha do Rio Sono.

A estrutura de apoio possui também acessos com calçamento, amplo espaço gourmet e casa de banhos. Toda a energia utilizada é captada através de energia solar: aquecimento de chuveiros, iluminação e refrigeração. A casa de banhos obedece a princípios ecologicamente corretos, com economia de água, aquecimento solar e sistemas completos acoplados aos vasos. 
Todo o trabalho realizado na construção do complexo foi executado por mão de obra local, utilizando matéria prima da região. Um redário ${ }^{3}$ se destaca no centro do jardim, com estrutura rústica de madeira coberta de palha, ideal para relaxar.

O Jalapão Ecolodge possui várias atividades e passeios turísticos de mínimo impacto nos limites da RPPN, a exemplo de caminhadas em trilhas ecológicas, chamada de "escalaminhada"4 sobre o Monte Catedral, canoagem, flutuação e boiacróss no Rio Soninho, raftting no Rio Novo, treeking, birdwatching e Bike Park (Figura 2), com $11 \mathrm{~km}$ de extensão para prática de Mountainbike e cicloturismo.

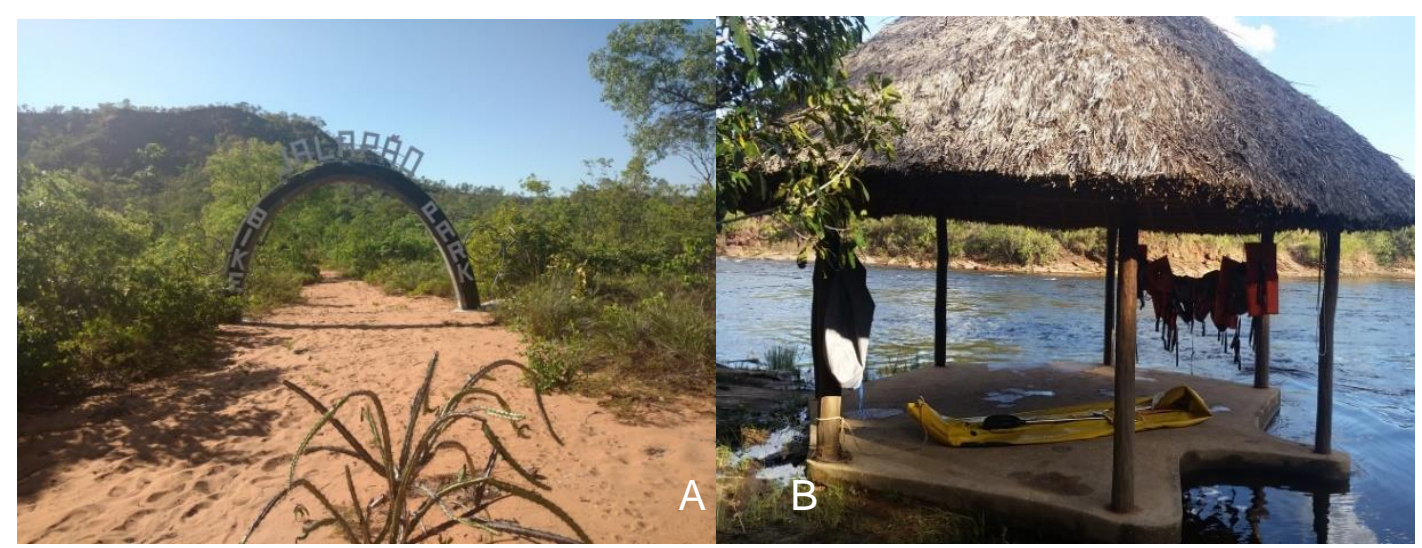

Figura 2: A: Bike Park; B: Rio Sono, local de canoagem e banho de rio.

Fonte: Pesquisa de campo, out./2016.

Figure 2: A: Bike Park; B: Sono River, place of canoeing and bath.

Source: Field survey, Oct./2016.

Todas as atividades ecoturísticas propostas no Jalapão Ecolodge permitem a contemplação da natureza, de uma forma ecologicamente não poluente e num ritmo que permita a percepção ambiental do ecossistema local, aliando ao conhecimento de espécies botânicas e observação da fauna local.

Apesar da intenção, segundo o proprietário, a RPPN Catedral do Jalapão ainda não possui plano de manejo. O plano de manejo de RPPN deverá, no âmbito federal, ser aprovado pelo IBAMA, conforme o Decreto 5.746 (BRASIL, 2006). De acordo com a Lei 9.985 (BRASIL, 2000, p.1), o plano de manejo consiste num documento técnico mediante o qual se estabelece o seu zoneamento e as normas que devem presidir o uso da área e o manejo dos recursos naturais, inclusive a implantação das estruturas físicas necessárias à gestão da unidade. O manejo é "todo e qualquer procedimento que vise assegurar a conservação da diversidade biológica e dos ecossistemas" e o zoneamento é a definição de setores "em uma Unidade de Conservação com objetivos de manejo e normas específicos, com o propósito de proporcionar os meios e as condições para que todos os objetivos da unidade possam ser alcançados de forma harmônica e eficaz".

De acordo o proprietário, as principais características da área que justificaram a iniciativa de transformar a área em uma RPPN foi o interesse 
na conservação da biodiversidade e do ecossistema local e principalmente devido à localização do monumento da Serra da Catedral, símbolo da RPPN. Quando questionado sobre o motivo da criação da RPPN Catedral do Jalapão que influenciaram na sua decisão, o gestor respondeu de acordo com as razões listadas no Quadro 01, conforme o grau de relevância:

\begin{tabular}{|c|c|c|c|c|}
\hline & $\begin{array}{c}\text { Nenhuma } \\
\text { importância }\end{array}$ & $\begin{array}{c}\text { Pouca } \\
\text { importância }\end{array}$ & Importante & $\begin{array}{l}\text { Extremamente } \\
\text { importante }\end{array}$ \\
\hline $\begin{array}{c}\text { Proteger espécies } \\
\text { ameaçadas }\end{array}$ & & & & 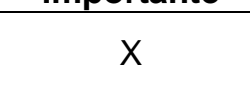 \\
\hline Propiciar pesquisa científica & & & $\mathrm{X}$ & \\
\hline $\begin{array}{l}\text { Proteger uma amostra } \\
\text { representativa do } \\
\text { ecossistema regional }\end{array}$ & & & & $\mathrm{x}$ \\
\hline Proteger cursos d'água & & & & $\mathrm{X}$ \\
\hline $\begin{array}{l}\text { Receber recursos por } \\
\text { serviços ambientais por } \\
\text { proteger a área }\end{array}$ & & $x$ & & \\
\hline $\begin{array}{l}\text { Ser beneficiado com a } \\
\text { isenção do ITR }\end{array}$ & $x$ & & & \\
\hline $\begin{array}{c}\text { Garantir a perpetuidade da } \\
\text { proteção da Área }\end{array}$ & & & & $\mathrm{x}$ \\
\hline $\begin{array}{l}\text { Desenvolver } \\
\text { empreendimento } \\
\text { ecoturístico }\end{array}$ & & & $\mathrm{x}$ & \\
\hline $\begin{array}{l}\text { Barrar a expansão do } \\
\text { agronegócio }\end{array}$ & & $\mathrm{x}$ & & \\
\hline $\begin{array}{c}\text { Propiciar maior } \\
\text { conectividade entre os } \\
\text { habitats }\end{array}$ & & & & $x$ \\
\hline $\begin{array}{l}\text { Contribuir com a relevância } \\
\text { ecológica da localização da } \\
\text { propriedade }\end{array}$ & & & & $\mathrm{X}$ \\
\hline $\begin{array}{l}\text { Galgar um status de } \\
\text { responsabilidade } \\
\text { socioambiental }\end{array}$ & & & $\mathrm{x}$ & \\
\hline $\begin{array}{c}\text { Propiciar a } \\
\text { recuperação/restauração de } \\
\text { áreas degradadas }\end{array}$ & & $\mathrm{x}$ & & \\
\hline $\begin{array}{c}\text { Preservação integral da } \\
\text { biota e atributos naturais, } \\
\text { sem interferência antrópica: }\end{array}$ & & & $X$ & \\
\hline Satisfação pessoal & & & & $\mathrm{X}$ \\
\hline
\end{tabular}

Quadro 01: Motivos para criação da RPPN Catedral do Jalapão.

Fonte: Elaboração própria (2017).

Table 01: Reasons for the creation of RPPN Catedral do Jalapão.

Source: Own elaboration (2017).

A Catedral do Jalapão possui uma vocação pautada numa perspectiva conservacionista associado ao desenvolvimento do ecoturismo e educação ambiental, buscando trabalhar da forma menos impactante possível, com novas práticas presentes no manejo pautado nos princípios da sustentabilidade ambiental dos recursos naturais da propriedade, como por exemplo: a separação e destinação dos resíduos sólidos e horta orgânica, a 
adoção de práticas da bioconstrução como as soluções de arquitetura que propiciam a economicidade de energia.

Quando questionado sobre o grau de relevância das razões que influenciaram na criação da RPPN, o proprietário aponta como de extrema importância a proteção de espécies ameaçadas; proteção de uma amostra representativa do ecossistema regional não só pelo tamanho, mas sim pela conectividade com o Parque Estadual do Jalapão e a proteção de cursos d'água, que graças ao manejo estabelecido, o local encontra-se livre de queimadas há quase 10 anos.

O proprietário pondera como de extrema importância a relevância ecológica da localização da RPPN, posto que a RPPN Catedral do Jalapão compõe o Mosaico de Unidades Conservação do Jalapão; assim como a importância de se propiciar a conectividade entre os habitats através do Corredor Ecológico da Região do Jalapão.

Outra questão relevante avaliada pelo proprietário como de extrema importância é a satisfação pessoal em resguardar uma área natural como RPPN e a garantia de perpetuidade de proteção da área definida como Reserva, o que assegura que seus esforços de conservação perpetuem no futuro, assegurando que seus descendentes (herdeiros) ou sucessores na gestão da área não consigam mudar a destinação conservacionista do local, conforme regras de criação das RPPN's (BRASIL, 2006).

Quanto ao quesito da preservação integral da biota e atributos naturais sem interferência antrópica, este foi julgado como importante, apesar de que seja permitida a visitação pública destinada à educação ambiental no espaço natural da RPPN, mediante a observância das normas de respeito com o ambiente que se destina ao uso indireto dos recursos naturais, segundo a legislação da SNUC (BRASIL, 2006). Outro quesito considerado importante para a criação da RPPN foi de galgar um status de responsabilidade socioambiental e desenvolver a prática do ecoturismo, alcançado em 2014 com o Jalapão Ecolodge.

Com relação à pesquisa cientifica, o proprietário considerara como relevante, visto que exerce a profissão de docente na Universidade Federal e desenvolve pesquisas na região desde 2005. Entretanto, aponta a existência de dificuldades para receber e apoiar essas pesquisas. Segundo o proprietário, ele desejaria que mais pesquisas fossem realizadas sobre a Ecologia das espécies, trabalhos de conservação de espécies endêmicas ou espécies mais vulneráveis, mas dada a dificuldade do setor de pesquisa das universidades do ponto de vista de recursos, o grau de demanda não seria alcançável.

Por fim, entre os questionamentos que representam pouca ou nenhuma relevância na criação da RPPN estão: receber recursos por serviços ambientais por proteger a área, ser beneficiado com a isenção do Imposto Territorial Rural - ITR, barrar a expansão do agronegócio e propiciar a recuperação/restauração de áreas degradadas. 


\section{Perfil do visitante da Catedral do Jalapão e o fluxo de visitação}

Nesse trabalho, foram pesquisados 59 visitantes do complexo, com 0 objetivo de conhecer o perfil do turista da Catedral do Jalapão, bem como o grau de satisfação quanto aos serviços oferecidos. Destes, $75 \%$ eram do sexo feminino e $25 \%$ do sexo masculino. Quanto ao Estado de origem, $55 \%$ vieram de São Paulo, 23\% do Rio de Janeiro e os demais são oriundos do Paraná, Tocantins, Bahia, Pernambuco, Paraíba e Distrito Federal.

Em relação à faixa etária, $37 \%$ dos pesquisados tem de 36 a 50 anos, $29 \%$ de 26 a 35 anos, $17 \%$ de 18 a 25 anos e o restante (17\%) tem de 51 a 60 anos. Quanto ao estado civil, $47 \%$ são casados, $46 \%$ solteiros, $5 \%$ divorciados e $2 \%$ viúvos. Estes dados revelam que o público que frequenta a RPPN é, no geral, jovem.

Em relação à profissão, $38 \%$ dos pesquisados trabalham no serviço público, $32 \%$ na iniciativa privada, $15 \%$ são profissionais liberais, $12 \%$ são estudantes e $3 \%$ são empresários. Quanto ao grau de escolaridade, a grande maioria (93\%) dos pesquisados afirmou ter ensino superior completo, enquanto apenas $7 \%$ só possuem ensino médio completo. Estas informações auxiliam a traçar o perfil médio dos turistas que visitam o local, compondo um quadro de certa forma elitizado. $O$ fato de que apenas $7 \%$ dos entrevistados possuem como grau máximo de escolaridade o ensino médio corrobora a afirmação acima. Os valores identificados se assemelham à média do ecoturista nacional, cujo nível de escolaridade superior completo chega a 57\% (KADOTA et al., 2004).

Quando questionados sobre o principal motivo da viagem à Catedral do Jalapão, 73\% responderam que seria 'relaxar e curtir a natureza', 19\% responderam 'aventura', $5 \%$ diversão e $2 \%$ outros motivos (Figura 3 ).

E sobre a quantidade de pessoas que os acompanharam na viagem, $42 \%$ disseram que viajam com 4 ou mais pessoas, $32 \%$ com uma pessoa, $12 \%$ com duas pessoas, $10 \%$ com três pessoas, e $4 \%$ viajaram sozinhos.

Com relação a motivação da viagem a pesquisa aponta que a maioria dos entrevistados (74\%) apontaram a natureza como o seu principal atrativo, conforme observado na Figura 3. Dentre os aspectos observados, atenta-se para o fato de que os turistas ressaltam a importância da conservação do ambiente, tanto para o turismo quanto para a qualidade de vida. 


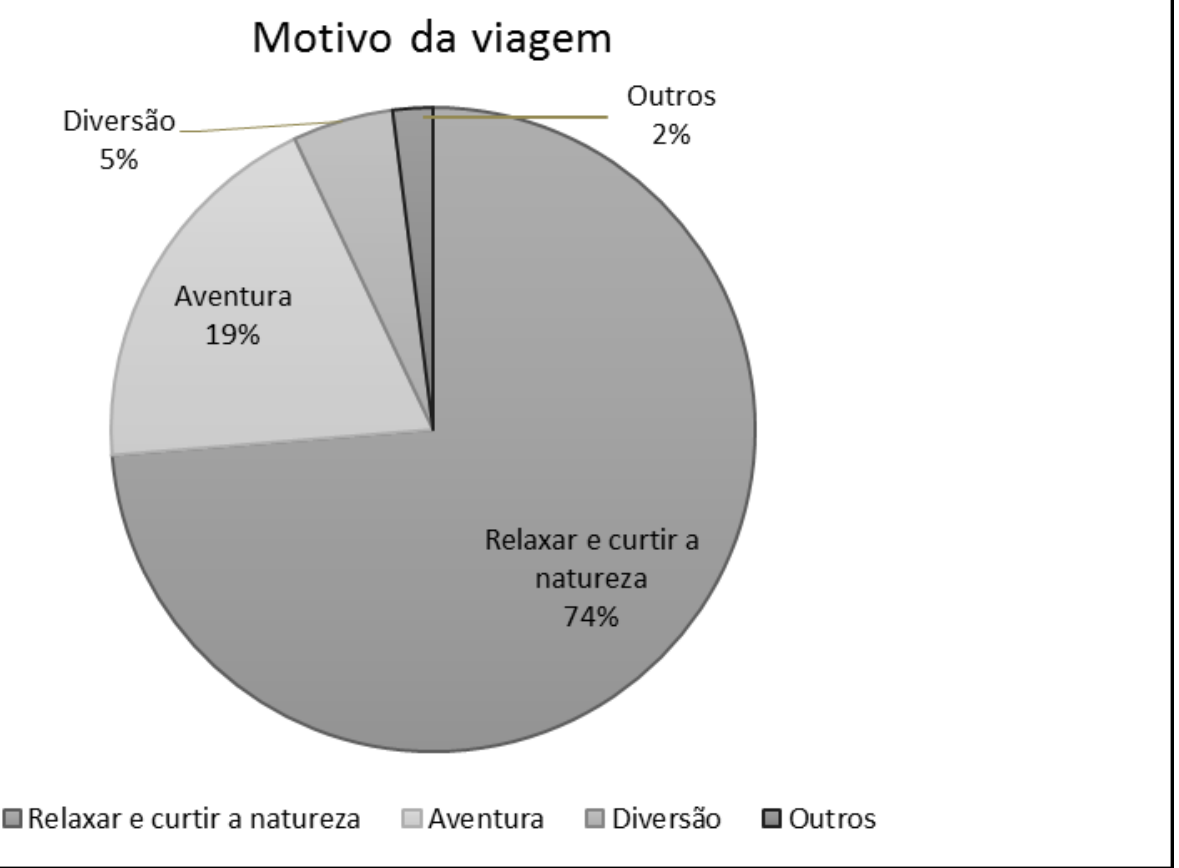

Figura 3: Principal motivo da viagem à RPPN. Fonte: Elaboração própria (2017).

Figure 3: Main reason for the trip to RPPN. Source: Own elaboration (2017).

Por outro lado, foram também inseridas algumas questões, de forma a perceber o grau de importância que os turistas conferem à conservação ambiental. A pesquisa constatou que $42 \%$ dos pesquisados desconheciam o fato de que a Catedral do Jalapão é uma Unidade de Conservação. Este dado é preocupante no que diz respeito a preservação ambiental, pois este desconhecimento pode levar os visitantes a cometerem atos que prejudiquem ou danifiquem o ambiente natural da RPPN.

A qualidade do destino reflete em uma alta taxa de indicação de terceiros para na escolha do local. Dos entrevistados, 53\% se interessaram em conhecer a propriedade devido à comentários de parentes e amigos que já visitaram o local, outros $29 \%$ viram pela internet, $7 \%$ por indicação de agências de viagens e o restante (11\%) por outras razões. Com isso são reforçados os diferenciais qualitativos da paisagem e do produto oferecido, ponto chave em um processo de gestão de um produto ecoturístico.

Sobre o meio de transporte utilizado para chegar no empreendimento ecoturístico, a grande maioria (95\%) utilizou de veículos com tração $4 \times 4$. Isto se deve ao acesso que é bastante complicado para carros pequenos, pois boa parte da estrada é de piçarra (estrada sem pavimentação asfáltica, de terra batida coberta por pedras pequenas de cor vermelha).

Quando questionados se conhecem outras regiões do Jalapão, 66\% dos pesquisados confirmaram, enquanto 34\% disseram não conhecer outros locais. Isto demostra que os visitantes gostam deste estilo de ambiente natural e das práticas turísticas que a região oferece. Entretanto, 97\% dos pesquisados estavam conhecendo o Ecolodge pela primeira vez. Em termos mercadológicos esse dado é expressivo, já que demonstra a volatilidade da demanda e a baixa fidelidade do turista ao destino. A pesquisa não apurou 
essa linha de forma mais profunda, mas algumas hipóteses podem ser levantadas para pesquisas futuras, relacionando a baixa fidelidade à distância do atrativo dos principais centros emissores ou ao seu custo.

Dos visitantes pesquisados, $71 \%$ disseram que fazia parte dessa viagem também visitar outros atrativos turísticos da região, e $85 \%$ deles viajaram com o auxílio de guia de turismo. A presença deste profissional na viagem da maioria dos visitantes da Catedral do Jalapão mostra 0 reconhecimento da profissão de guia e o profissionalismo de como o turismo está se desenvolvendo, além da geração de empregos no setor.

Sobre o tempo de permanência no Ecolodge, $86 \%$ dos pesquisados ficaram um dia, com pernoite, desfrutando de todo o espaço. Enquanto $11 \%$ eram excursionistas, permanecendo apenas o dia, sem dormir, e o restante (3\%) ficou mais dias hospedados no empreendimento.

Em relação ao tipo de acomodação utilizada, $75 \%$ dos visitantes utilizaram as chamadas 'buritibanas', $22 \%$ o bangalô e $3 \%$ dormiam em barracas no local destinado ao camping. Sobre as atividades desenvolvidas no empreendimento, $59 \%$ dos visitantes fizeram caminhadas nas trilhas ecológicas da Reserva, 53\% tomaram banho de rio, 22\% praticaram canoagem ou boiacross, $22 \%$ fizeram uma 'escalaminhada' no Monte Catedral, $17 \%$ realizam trilhas com bicicleta, $8 \%$ raftting, entre outras atividades.

\section{A qualidade dos serviços prestados e a satisfação do turista}

Para a avaliação do grau de satisfação do turista quanto ao local, utilizou-se uma escala qualitativa com quatro graus diferentes. Dirigiu-se 0 foco da pesquisa para os equipamentos e infraestruturas do local, considerando que todos os turistas tiveram contato direto com estes, facilitando a sua avaliação. As Figuras 4 e 5 sintetizam os itens avaliados e seus respectivos percentuais na escala proposta.

$\mathrm{Na}$ análise da escala qualitativa utilizada, o item "excelente" se sobressaiu aos demais, com uma média de $72 \%$ dos apontamentos realizados. Somado ao item "bom", atinge-se um total de $96 \%$ de avaliações positivas para o empreendimento. Os itens que mais pesaram na avaliação foram: a limpeza (81\% excelente, $19 \%$ bom), as acomodações (78\% excelente, $15 \%$ bom) e a alimentação (69\% excelente e $28 \%$ bom). Por outro lado, os elementos que mais pesaram na avaliação negativa do local foram: a sinalização ( $2 \%$ péssimo, 3\% regular) e as acomodações ( $7 \%$ regular). Apesar disso, é importante ressaltar que ambos os itens possuíram uma parcela significativa de apontamentos na escala excelente: 66\% para sinalização e $78 \%$ para acomodações.

A avaliação positiva das acomodações está relacionada ao conforto e estrutura, principalmente, das 'buritibanas', já que $75 \%$ dos visitantes se hospedaram nestes locais. Sobre as atividades ecoturísticas, como caminhadas, canoagem, trilhas de bicicleta e banhos de rio, 67\% gostaram bastante, mostrando uma grande aprovação da oferta turística local. 


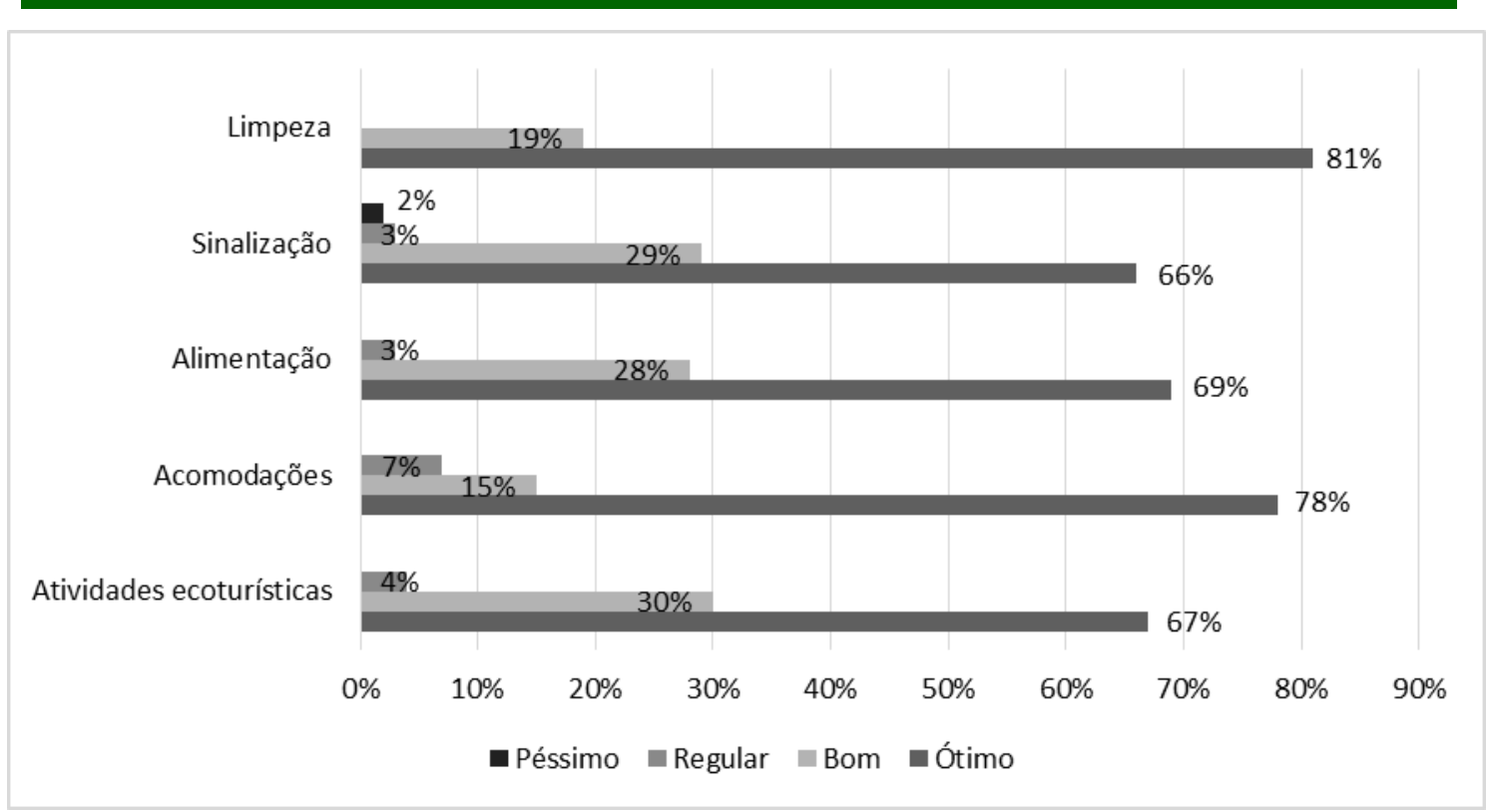

Figura 4: Opinião sobre a Catedral do Jalapão. Fonte: Elaboração própria (2017).

Figure 4: Opinion about the Catedral do Jalapão. Source: Own elaboration (2017).

A grande maioria dos visitantes (86\%) considerou que a preservação ambiental e o atendimento dos funcionários são 'ótimos'. O fato dos visitantes observarem a preocupação do empreendimento com a preservação ambiental é interessante, já que apenas $58 \%$ dos visitantes sabiam que o local é uma Reserva Particular de Preservação Natural. Isto mostra como a estrutura física do local está em equilíbrio com o meio ambiente, indo de acordo com as exigências de uma UC.

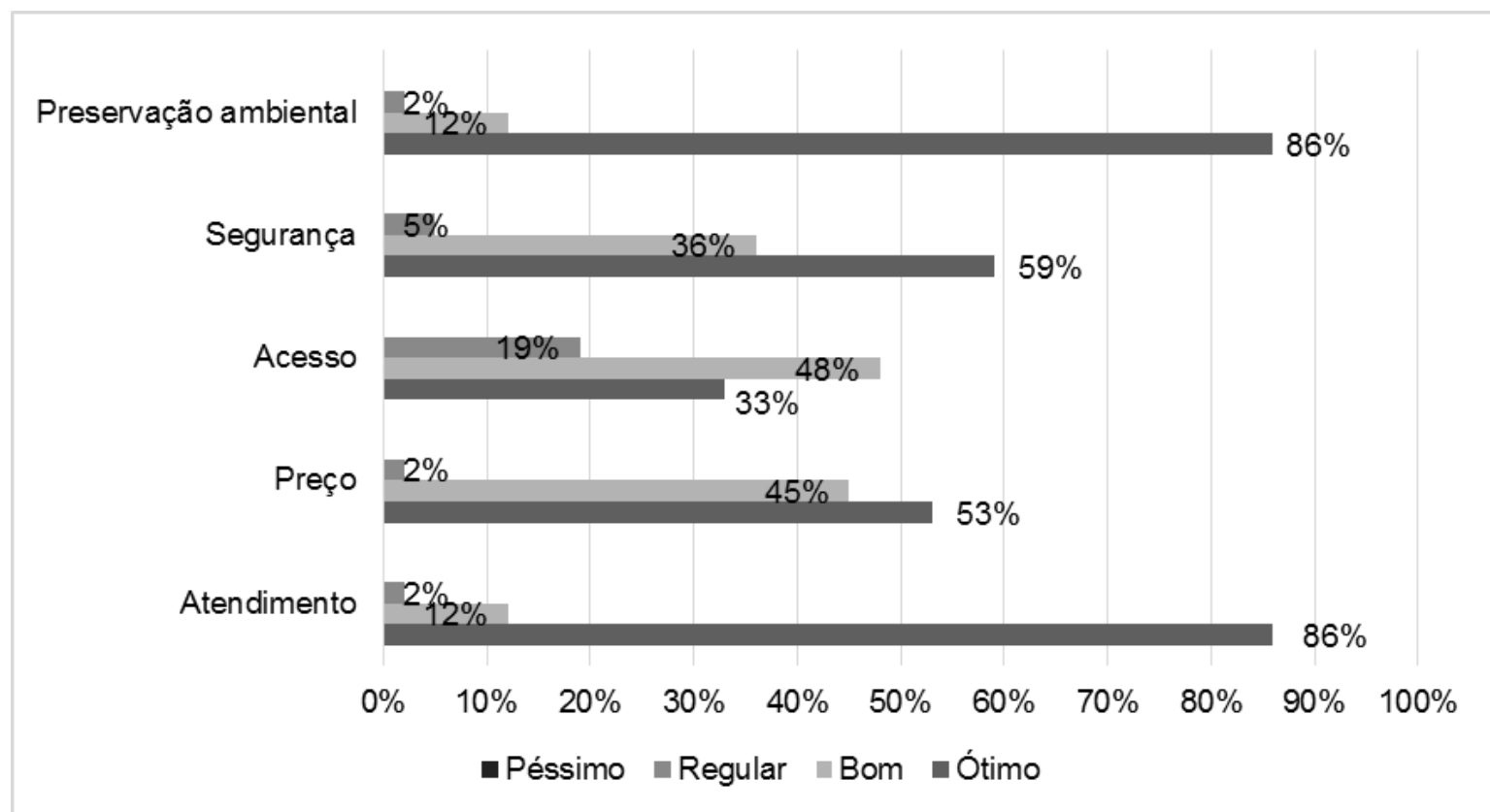

Figura 5: Opinião sobre a Catedral do Jalapão - itens 2. Fonte: Elaboração própria (2017).

Figure 5: Opinion about the Catedral do Jalapão - items 2. Source: Own elaboration (2017). 
A Figura 5 mostra ainda que houveram divergências de opinião em relação à segurança, acesso e o preço cobrado. Para 59\% dos visitantes, a segurança do empreendimento é classificada como 'ótima', enquanto para $36 \%$ 'boa' e $5 \%$ 'regular'. Este dado se refere a segurança das unidades habitacionais do tipo buritibanas, que possui apenas cortina de isolamento. Isso reflete o grau de insegurança e medo vivenciado atualmente pelas pessoas no ambiente urbano.

Quanto ao acesso, somente 33\% consideraram 'ótimo', 48\% 'bom' e $19 \%$ 'regular'. Isto se deve às dificuldades encontradas para se chegar à RPPN, como explicada anteriormente. E em relação aos preços, a maioria considerou compatível ao que é ofertado, sendo que 53\% disseram ser 'ótimo' e 45\% 'bom'.

Outros dados encontrados mostram como a Catedral do Jalapão está preocupada com a preservação do meio ambiente local: $78 \%$ dos pesquisados disseram que perceberam ações de educação ambiental no empreendimento e $97 \%$ disseram que não visualizaram impactos ambientais na RPPN. Estes dados são muito importantes para confirmar que a estrutura física e atividades desenvolvidas no local foram planejadas para provocar o mínimo de impacto possível ao ambiente natural, levando seus visitantes a um contato equilibrado com a natureza, que é uma das características do ecoturismo.

O ecoturismo desenvolvido na Catedral do Jalapão está funcionando tão bem, que $98 \%$ dos pesquisados disseram que pretendem voltar outras vezes ao empreendimento e $100 \%$ recomendariam a visita a amigos e parentes.

\section{Considerações Finais}

A iniciativa de criar uma RPPN pode ser considerada um idealismo por parte de proprietários particulares que acreditam na proteção da natureza como forma de colaborar com a manutenção dos ecossistemas. Nesta perspectiva, sobre o legado conservacionista das Reservas Particulares do Patrimônio Natural, percebeu-se com este trabalho a importância desses empenhos, tanto no meio ambiente quanto na prática de uma consciência ecológica, pautada em práticas sustentáveis de respeito ao ecossistema local e na busca de um ambiente saudável e equilibrado.

Com esta pesquisa, observou-se que a proposta da RPPN Catedral do Jalapão atende seus objetivos, analisando desde a sua estrutura física, com espaços projetados de acordo com as premissas da arquitetura sustentável, até na prática das atividades de ecoturismo. Verificou-se que toda a energia utilizada é captada através da energia solar e todo o trabalho realizado na construção do complexo foi executado por mão de obra local, utilizando matéria prima da região.

Durante a entrevista com o proprietário, foi apontado que as principais razões para a criação da RPPN foi a proteção de espécies ameaçadas e a proteção de uma amostra representativa do ecossistema regional. Foi 
mencionado também a questão da relevância ecológica da localização da RPPN e sua satisfação pessoal em resguardar esta área natural.

Durante a pesquisa, constatou-se que boa parte dos visitantes eram oriundos do Estado de São Paulo, que chegaram ao empreendimento através de carros com tração $4 \times 4$. Sobre o principal motivo da viagem à Catedral do Jalapão, a maioria afirmou: 'relaxar e curtir a natureza'. Uma questão chamou a atenção: $42 \%$ dos pesquisados desconheciam o fato de que a Catedral do Jalapão é uma Unidade de Conservação. Isto é preocupante no que diz respeito a preservação ambiental, pois este desconhecimento pode levar os visitantes a cometerem atos que prejudiquem ou danifiquem o ambiente natural da RPPN.

Apesar deste desconhecimento, por parte de alguns visitantes, a maioria dos pesquisados considerou que a preservação ambiental do local é ótima, mostrando como a estrutura física do empreendimento está em equilíbrio com o meio ambiente, cumprindo as exigências de uma UC.

Em relação à prática do ecoturismo, percebeu-se que os visitantes realizaram diversas atividades na Reserva, principalmente trilhas ecológicas, banhos de rio, canoagem ou boiacross. O retorno positivo destas atividades foi constatado, na pesquisa, com a aprovação da grande maioria dos pesquisados, que ainda afirmaram que pretendem voltar outras vezes ao empreendimento e recomendar a visita a amigos e parentes.

Com o aprofundamento da pesquisa e as observações diretas é possível notar que a RPPN Catedral do Jalapão vem efetivamente cumprindo com seu papel e desenvolvendo suas atividades em consonância tanto com o ecoturismo de base sustentável como no empenho de promoção da conservação e manutenção do equilíbrio ecológico não só na área da Reserva como também na propriedade como um todo.

A RPPN Catedral do Jalapão exerce efetivamente importante função na manutenção do equilíbrio ecológico de mananciais e de uma amostra representativa do Cerrado. Como parte integrante no Mosaico de Unidades de Conservação do Jalapão e do Corredor Ecológico do Jalapão, exerce possivelmente um papel na conectividade de habitats na região, promovendo a manutenção saudável de populações de algumas espécies silvestres.

Assim, podemos perceber que a Catedral do Jalapão tem buscado através de suas práticas, cumprir com o papel socioambiental para o qual foi definida, sendo um modelo de sustentabilidade e boas práticas associadas ao ecoturismo. Mostra, também, que com planejamento e boa gestão é possível desenvolver o ecoturismo de uma forma mais sustentável. 


\section{Referências Bibliográficas}

BENI, M. Análise estrutural do turismo. São Paulo: SENAC, 2003.

BRASIL. ICMBio. Atlas do Corredor Ecológico da Região do Jalapão. 2. ed., 2013a. Disponível em: <http://www.icmbio.gov.br/projetojalapao>. Acesso em: 15 maio. 2017.

BRASIL. ICMBio. Projeto Corredor Ecológico da Região do Jalapão: Subsídio para o Plano Estratégico Mosaico do Jalapão. 2013b. Disponível em: <http://www.icmbio.gov.br/projetojalapao>. Acesso em: 15 maio. 2017.

BRASIL. Lei 5.746, de 5 de abril de 2006. 2006. Disponível em: $<$ http://www.planalto.gov.br/ccivil 03/ Ato2004-

2006/2006/Decreto/D5746.htm >. Acesso em: 26 abr. 2017.

BRASIL. Lei 9.985, de 18 de julho de 2000. 2000. Disponível em: $<$ http://www.planalto.gov.br/ccivil 03/leis/L9985.htm>. Acesso em: 26 abr. 2017.

BRASIL. MMA. Diretrizes para uma política nacional de ecoturismo. Brasília: MMA, 1994. Disponível em: $<$ http://www.mma.gov.br/estruturas/sedr proecotur/ publicacao/140 publica cao20082009043710.pdf >. Acesso em: 1 maio 2017.

BRASIL. MMA. Diretrizes para Visitação em Unidades de Conservação Áreas Protegidas. Brasília: Ministério do Meio Ambiente, 2006. Disponível em: <http://www.mma.gov.br/estruturas/ascom boletins/ arquivos/livro.pdf>. Acesso em: 1 maio 2017.

BRASIL. MMA. Pilares para a sustentabilidade financeira das Unidades de Conservação. 2. ed. Série áreas protegidas do Brasil, 7. Brasília: MMA, $2009 . \quad$ Disponível em $<$ http://www.mma.gov.br/estruturas/sbf2008 dap/ publicacao/149 publicaca o16122010113443.pdf >. Acesso em: 1 maio 2017.

BRASIL. MMA. Portaria no 434, de 29 de setembro de 2016: cria o Mosaico do Jalapão. Diário Oficial [da] República Federativa do Brasil, Brasília, DF, 2016. Disponível em: $<$ http://www.lex.com.br/legis 27192386 PORTARIA N 434 DE 29 DE SE TEMBRO DE 2016.aspx>. Acesso em: 15 maio 2017.

BRASIL. Ministério do Turismo. Ecoturismo: orientações básicas. 2. ed. Brasília: Ministério do Turismo, 2010.

BRASIL. Ministério do Turismo. Programa de Regionalização do Turismo - Roteiros do Brasil: Conteúdo Fundamental - Turismo e Sustentabilidade. Brasília, 2007.

CEGANA, A.C.; TAKAHASHI L.Y. Situação atual do planejamento e uso público das Reservas Particulares do Patrimônio Natural no Estado do Paraná. Natureza \& Conservação, v. 3, n.1, p. 83-92, 2005.

DENCKER, A.F.M. Pesquisa em turismo: planejamento, métodos e técnicas. 9. ed. rev. e ampl. São Paulo: Futura, 1998. 
KADOTA, D.; HADDAD, E.; RABAHY, W.A. Aspectos do ecoturismo: perfil do turismo praticado em parques nacionais e áreas naturais conservadas. Turismo em números, Caderno de estatísticas, v. 35. São Paulo, 2004.

MEDEIROS, R.; YOUNG; C.E.F.; PAVESE, H.B.; ARAÚJO, F.F.S. Contribuição das Unidades de Conservação brasileiras para a economia nacional: Sumário Executivo. Brasília: UNEP-WCMC, 2011. Disponível

em: $<$ http://www.icmbio.gov.br/portal/images/stories/comunicacao/estudocontribui cao.pdf>. Acesso em: 1 maio 2017.

NELSON, S.P.; PEREIRA, M.É. (Orgs.). Ecoturismo: práticas para turismo sustentável. Manaus: Valer/Uninorte, 2004.

OMT. Guia de desenvolvimento do turismo sustentável. Tradução: Sandra Netz. Porto Alegre: Bookman, 2003.

PIRES, P.S. Dimensões do ecoturismo. São Paulo: SECAC, 2002.

RUSCHMANN, D. Turismo e Planejamento Sustentável - a Proteção do Meio Ambiente. São Paulo: Papirus, 2000.

SANTOS, I.E. Manual de métodos e técnicas de pesquisa científica. 12. ed. rev. e atual. Niterói, RJ: Impetus, 2016.

SILVA, D.L.B. Turismo em Unidades de Conservação: Contribuições para a prática de uma atividade turística sustentável no Parque Nacional dos Lençóis Maranhenses. 2008. 206 f. Dissertação de Mestrado. Centro de Desenvolvimento Sustentável, Universidade de Brasília, Brasília, 2008.

SOARES, E.J.; ADORNO, L.F. O sistema de gestão ambiental das RPPN's do stado do Tocantins. Anais. VII Congresso Brasileiro de Geógrafos. Vitória, 2014. Disponível em: <http://www.agb.org.br/>. Acesso em: 23 maio 2017.

TIES - THE INTERNATIONAL ECOTOURISM SOCIETY. What is ecotourism? Disponível em: <https://www.ecotourism.org/what-isecotourism>. Acesso em: 1 maio 2017.

VERA, J.F; PALOMEQUE, F.L; MARCHENA, M.J; ANTON, J. Análisis territorial del turismo. Barcelona: Editora Ariel, 1997.

\section{Notas:}

1 O alojamento recebeu este nome devido a sua cobertura ser construída com a palha da palmeira buriti, típica da região.

2 Banheira de Hidromassagem abastecida com água aquecida.

${ }^{3}$ Local onde ficam várias redes.

4 Caminhada em trilhas de ascensão, onde nos lugares mais difíceis de subir, usa-se as mãos em raízes ou pedras que existem no caminho, sem a necessidade do uso de cordas ou semelhantes. 
Janaina Maria Andrade Aires Fonseca: Instituto Federal de Educação, Ciência e Tecnologia do Tocantins, Palmas, TO, Brasil.

E-mail: janaina@ifto.edu.br

Link para o currículo Lattes: http://lattes.cnpq.br/0266792882870843

Stella Maria Carvalho de Melo: Instituto Federal de Educação, Ciência e Tecnologia do Piauí, Teresina PI, Brasil.

E-mail: stella@ifpi.edu.br

Link para o currículo Lattes: http://lattes.cnpq.br/4251088950203542

Wesley Gomes de Carvalho: Instituto Federal de Educação, Ciência e Tecnologia do Tocantins, Palmas, TO, Brasil.

E-mail: wesleygomes101@gmail.com

Link para o currículo Lattes: http://lattes.cnpq.br/2904021275078489

Data de submissão: 27 de outubro de 2017

Data de recebimento de correções: 11 de dezembro de 2017

Data do aceite: 11 de dezembro de 2017

Avaliado anonimamente 